\title{
Planning Ahead? An Exploratory Study of South Korean Investigators' Beliefs About Their Planning for Investigative Interviews of Suspects
}

\author{
Jihwan Kim $^{1}$ - Dave Walsh ${ }^{1}$ (D) Ray Bull ${ }^{1} \cdot$ Henriette Bergstrøm $^{1}$
}

Published online: 16 November 2017

(C) The Author(s) 2017. This article is an open access publication

\begin{abstract}
Preparation and planning has been argued to be vitally important as to how effectively investigators undertake their interviews with suspects. Yet, it has also been found in previous research that investigators admit that they plan only occasionally, often attributing insufficient time as a reason for not undertaking the task. Employing a novel research paradigm that utilised theoretical foundations concerning planning, the present study explored empirically 95 South Korean financial crime investigators' views, using a selfadministered questionnaire. With the use of secondgeneration statistical modelling, an understanding was developed of the relative relationships between various concepts (which had themselves emerged from an established theoretical framework of planning that had been further extended to accommodate the context of the present study). The study found that perceived time pressures actually showed a very low association with interview planning. Rather, investigators' self-belief as to their own capability alongside workplace culture was each found to have stronger associations with investigators' intentions to plan for their interviews. As such, we argue that there should be more focus on improving occupational culture relating to interview planning, while developing training programs that identify, evaluate, and enhance investigators' planning skills. Implications for practice are therefore discussed.
\end{abstract}

Keywords Interview planning $\cdot$ PEACE model $\cdot$ Investigative interviewing $\cdot$ Fraud investigation $\cdot$ South Korean policing

Dave Walsh

d.walsh@derby.ac.uk

1 Department of Social Sciences, University of Derby, 1 Friar Gate Square, Agard Street, Derby DE1 1DZ, UK

\section{Introduction}

Police interviewing of suspects is one of the most crucial stages in criminal investigations (Hartwig et al. 2005a, b; Milne and Bull 1999). Through an interview, the police can obtain valuable information that can assist in solving a criminal case (Leo 2008). In some cases, an interview can also lead to a confession or admission of guilt, which, in turn, will make prosecution easier (Kassin 2008; Stephenson and Moston 2008). Because of its importance, multiple models for interviews have been proposed and utilised depending on the jurisdiction (e.g. the Reid model in North America; Leo 2008; the PEACE model in the UK; Shepherd and Griffiths 2013). To ensure the success of such models, the interviewers themselves are central to the process (Leo 2008), and Baldwin (1993) identified the qualities of a good interviewer through a thorough analysis of police interviews. He described that good officers should know the relevant law, study the available evidence, and think of the best structure of the interview. Soukara et al. (2002) also found that preparation was considered by police detectives to be a core element of successful suspect interviewing.

It has, however, only been in the last 20 years or so that interview training has emphasised the importance of planning ahead of interviews (Scott et al. 2015). Despite such training, field studies conducted in the UK suggest concerns with some of the interview skills that are believed to be associated with planning (Clarke and Milne 2001; Walsh and Bull 2010; Walsh and Milne 2008). Walsh and Milne (2007) found that, while most investigators acknowledged the importance of planning, far fewer actually said they undertook the task (see also Baldwin 1993; Cherryman and Bull 2001; Clarke and Milne 2001; Walsh and Bull 2011). The main reason offered was that they had insufficient time to plan. It is, however, not known whether this given reason is a valid one. Moreover, 
previous research has tended to explore how much criminal investigators prepare for interviewing rather than what factors influence investigators' decisions whether or not to plan (Clarke and Milne 2001; Walsh and Bull 2010). As a result, little remains known about actual planning and preparation of investigative interviews. The present study is the first study known to the authors that aims to examine which matters (including whether time pressure is responsible for not planning interviews or whether other reasons might be more strongly associated).

\section{Planning for Investigative Interviews}

An early definition of planning for investigative interviews described the task as "the mental process of getting ready to interview" and preparation as "considering what needs to be made ready prior to interview. It includes such things as the location, the environment and the administration" (Central Police Training Unit (CPTU) 1993, p. 1, cited in Milne and Bull 1999, p. 159). Since that initial clarification, other researchers have provided suggestions as to the sub-tasks appropriate to planning (McGurk et al. 1993; Milne and Bull 1999; National Crime Faculty (NCF) 1996; Schollum 2005). Schollum (2006) aggregated these tasks for all investigative interviewing contexts, including those involving victims and witnesses (see Table 1).

Further activities include the following: (i) contingency planning for the suspect's potential defence(s), (ii) considering the method/order of disclosing several items of evidence/information, and (iii) organising the sequence of topics and questions each need to be added to Table 1 (Dando and Bull 2011; Hartwig et al. 2006; Walsh and Bull 2015).

The importance of pre-interview groundwork has been repeatedly mentioned in the literature as a pivotal attribute of good interviewers (Baldwin 1993; Bull 2013; Cherryman and Bull 2001; Soukara et al. 2002; Walsh and Bull 2010; Walsh

Table 1 Tasks required when planning for interviews

Task

- Understanding the purpose of the interview

- Obtaining as much background information as possible on the incident under investigation, including (for suspects) information on the person to be interviewed

- Defining the aims and objectives of the interview

- Understanding and recognising the points to prove

o Assessing what evidence is available and from where it was obtained

o Assessing what evidence is needed and how it can be obtained

○ Understanding the legislation and associated guidelines and considerations

- Preparing the mechanics of the interview (attending to exhibits, logistics, venue, equipment functioning, seating, and so on) and Milne 2008). Planning before interviewing victims, witnesses, and suspects has been incorporated within a prescribed model of interviewing in England and Wales (i.e. PEACE, an acronym for its recommended five stages of planning, engaging and explaining, account gathering, closing, and evaluating interviews - see Shepherd and Griffiths 2013 for a more detailed explanation of the model). Since its introduction in the 1990s in England and Wales, various other countries have begun to employ the model (e.g. Scandinavia, Canada, and Australia, albeit on occasions in adapted forms, see Bull 2014; Walsh et al. 2016). Regardless of such modifications, it has been commonly contended that investigators should conduct substantial groundwork ahead of interviews.

Research examining interview planning and preparation has mostly been conducted as part of overall field evaluations of the PEACE model (Clarke and Milne 2001; Walsh and Milne 2008; Walsh and Bull 2010). Such research has tended to judge how well interview preparation has been conducted by examining if, for example during interviews, investigators appeared to (i) be familiar with the case details, (ii) have actually undertaken groundwork beforehand, (iii) be prepared when faced with alibis and the like from suspects, (iv) conduct the interview in a logical order of topic development, and (v) be familiar with the legal points needed to be proven concerning the suspected offences under investigation. However, research examining what they actually do in terms of preparation for interviews remains rare. Regardless, research has often found that investigators admitted to undertaking little or no planning ahead of interviews, despite professing its importance (Walsh and Milne 2007). Even more uncommon in prior research is an exploration of what factors appear to be associated with investigators' decisions whether or not to plan.

Important to investigator decision-making (i.e. in the context of the present study, whether to plan) may well be an investigative mindset (Mortimer and Shepherd 1999; Shepherd and Griffiths 2013). Defectiveness in decisionmaking (e.g. developing either a single or premature hypothesis, confirmation bias or stereotyping) has been repeatedly mentioned as a critical factor in investigative failures (Ask and Granhag 2005; Hill et al. 2008; Kassin et al. 2003; Rassin et al. 2010; Rossmo 2009). Despite this, little research had been conducted into what influences investigators' decision-making (Fahsing and Ask 2013). Shepherd and Griffiths (2013) suggest that various actual or perceived workplace pressures may lead investigators to decide upon more expedient ways of investigation, describing this state as one of "defensive avoidance" (Janis and Mann 1977). Such a notion (as a means of coping with decisional conflict) in the context of interview planning is manifest in the (i) minimisation of mental demands, (ii) evasion of complex judgement, and (iii) undertaking detailed investigation (Shepherd and Griffiths 2013). Such a situation, for example, may lead to 
the generation of a premature and single-case hypothesis, reflecting only minimal mental effort and expeditious action (which supports a pre-determined case theory). Accordingly, as thorough planning requires exerted cognitive effort (rather than avoidance), investigators possessing a high need for cognitive closure (see Kruglanski and Webster 1996) might be reasonably assumed to display a relatively low level of planning.

Mortimer and Shepherd (1999) have also argued that investigators' mindset influences pre-interview activities such as gathering and analysing information. Investigators' own schemata and confirmation biases may act as critical elements in accessing, processing, interpreting, and evaluating such information. This can lead to potentially erroneous decisionmaking throughout the entire investigation (see Shepherd and Griffiths 2013). Mortimer (1994) found that many investigators had a confession-seeking bias tendency, which affected how, and whether, they undertook subsequent information gathering. Other studies have also found that most investigators presume suspects to be guilty before an interview takes place (Fahsing and Ask 2013; Walsh and Bull 2011; Walsh and Milne 2007). Mortimer (1994) also contended that police investigators' occupational norms influence investigators' reasoning, judgement, and decision-making. Following these arguments, cognitive factors and the occupational culture may well also account for attitudes towards pre-interview investigative activity, including planning.

Another factor that might well influence investigators' decision-making as to whether or not to plan thoroughly (if at all) concerns their own estimations as to how effectively they conduct interviews without having sufficient preparation. A recent study (Walsh et al. 2017) found that investigators consistently over-estimate their interview skills, compared to an independent assessment of the same interviews (which found their skills generally to be at mediocre levels). It might be reasonably presumed that interviewers, lacking selfawareness as to their lack of competence in interviewing skills, might fail to connect such shortfalls to a lack of planning and preparation, particularly as it has been found they rarely evaluate their own interview performance (Walsh and Milne 2007). Moreover, field studies of investigative interviews have found strong correlations between planning skills and subsequent interview performance (Clarke and Milne 2001; Walsh and Bull 2010, 2015). Walsh and Bull (2010) found that those interviewers, whose planning skills were rated as skilled, more often than not obtained a detailed account from suspects (being the aim of the PEACE model), while those interviewers rated as least skilled almost always only obtained fractional accounts.

In addressing the large research gap regarding what factors determine whether interviewers decide whether or not to plan, it was necessary to operationalise the construct of planning for investigative interview. Based on the authors' expertise and thorough understanding of the interview process, planning for interviews with suspects in the present study is understood as: "investigators' constructive preparation activity for interviewing suspects, which involves setting specific aims and objectives, planning for potential defences, and organising an appropriate sequence of topics, questions and evidence/information disclosure in order to fulfil the purpose of the interview (that is, the gathering of a reliable and comprehensive account)".

\section{Theoretical Framework of Investigative Interview Planning}

In addition to such operationalisation of interview planning, we also established that there were no suitable measurement tools available to assess planning in an investigative interview context. As such, it was necessary to create one for the current study. This was grounded in theoretical perspectives that will be discussed in the current section. The theory of planned behaviour (Ajzen and Fishbein 2000; Fishbein and Ajzen 1975) was adapted as a framework for the present study (see Fig. 1). In brief, the theory accords that human behaviour is anchored by three kinds of beliefs: behavioural beliefs (i.e. attitude towards the behaviour), normative beliefs (i.e. subjective norm), and control beliefs (i.e. perceived behavioural control) (Ajzen 2006). Each type of belief is argued to effect, either favourably or unfavourably, subsequent components (Ajzen 2006).

Subjective norm, according to Ajzen (1991), relates to the possible presence of any social pressure (whether approval or disapproval) that effects the act of planning, which may be evident in strong organisational cultures such as policing (Davis 2013; Mortimer 1994). Perceived behavioural control has two aspects (i.e. internal and external). The former is thought to be associated with Bandura's "perceived selfefficacy" concept (1982), being found to mediate participants' perseverance on solving intellectual problems (Cervone and Peake 1986). External factors (such as perceived time pressure-see Walsh and Milne 2007) might be related to "perceived controllability over behaviour" (Conner and Armitage 1998, p. 1439). Individuals' intentions represent the motivational factors which influence their behaviour, indicating how much people will exert effort in order to perform the behaviour. Conner and Armitage (1998, p.1450) argued, however, that "intentions do not always lead to the successful enactment of behaviour".

Investigators' decision-making was also incorporated into the framework. Investigative mindset and defensive avoidance are argued to be integral components of the concept of the need for cognitive closure (or NFCC; see Kruglanski 1989, 1996). NFCC refers to individuals' preference for unambiguity, with those assessed with a high need being characterised by a tendency to form quick judgements based 


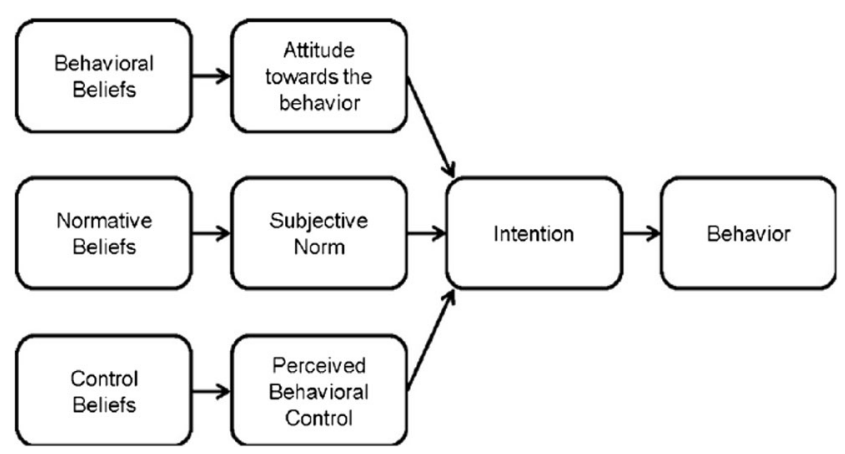

Fig. 1 Structural model of the theory of planned behaviour (Ajzen 2006)

on a solitary hypothesis, despite inconclusive evidence, while avoiding others' dissenting viewpoints (Kruglanski and Webster 1996). While Ask and Granhag (2005) did not find confirmation bias linked to NFCC among investigators, the current study examined whether NFCC is associated with insufficient planning.

In summary, in building a theoretical framework of planning for interviews with suspects (see Fig. 2), the present study suggests an exploratory model of investigators planning, based on the existing theory of planned behaviour, while incorporating the two additional factors of NFCC, and perceived time pressure.

In light of the foregoing, we hypothesised that there would be positive associations between interviewers' (i) attitudes towards undertaking the planning task, (ii) cultural expectations and beliefs concerning the task, (iii) beliefs as to their own ability to undertake interviews efficaciously without thorough planning, and (iv) perceived planning intent and planning behaviour. In addition, it was hypothesised that "time pressure" and NFCC would have a moderating effect on the relationship between intention and planning.

\section{Method \\ Materials}

A questionnaire was developed following the above theoretical framework. Having first obtained ethical approval from the authors' home university, the questionnaire (see Appendix 1) was successfully piloted with 15 investigators (i.e. no issues of ambiguity were found with the questions, while reporting relative ease in both understanding and completing the questionnaire). The instrument firstly involved a series of demographic questions relating to gender, rank, and length of professional experience. Three dichotomous questions were also asked relating to respondents' experience/views concerning training (in either the PEACE model or any preparation training). Thirty items associated with the theory of planned behaviour (TPB) were assessed using a seven-point Likert scale, where $1=$ Strongly disagree and $7=$ Strongly agree. The 15 NFCC-related questions followed the work of Roets and Van Hiel (2011) using an ascending six-point Likert scale, where $6=$ Strongly agree). Each of the two sets of questions was interspersed. Further, some questions were inversely coded (see Appendix 1: reverse coded items $=$ Nos. 2, 10, 19, 22, and 23 TPB questions; Nos. 2, 10 , and 15 of the NFCC ones).
Fig. 2 Theoretical model of interview planning behaviour

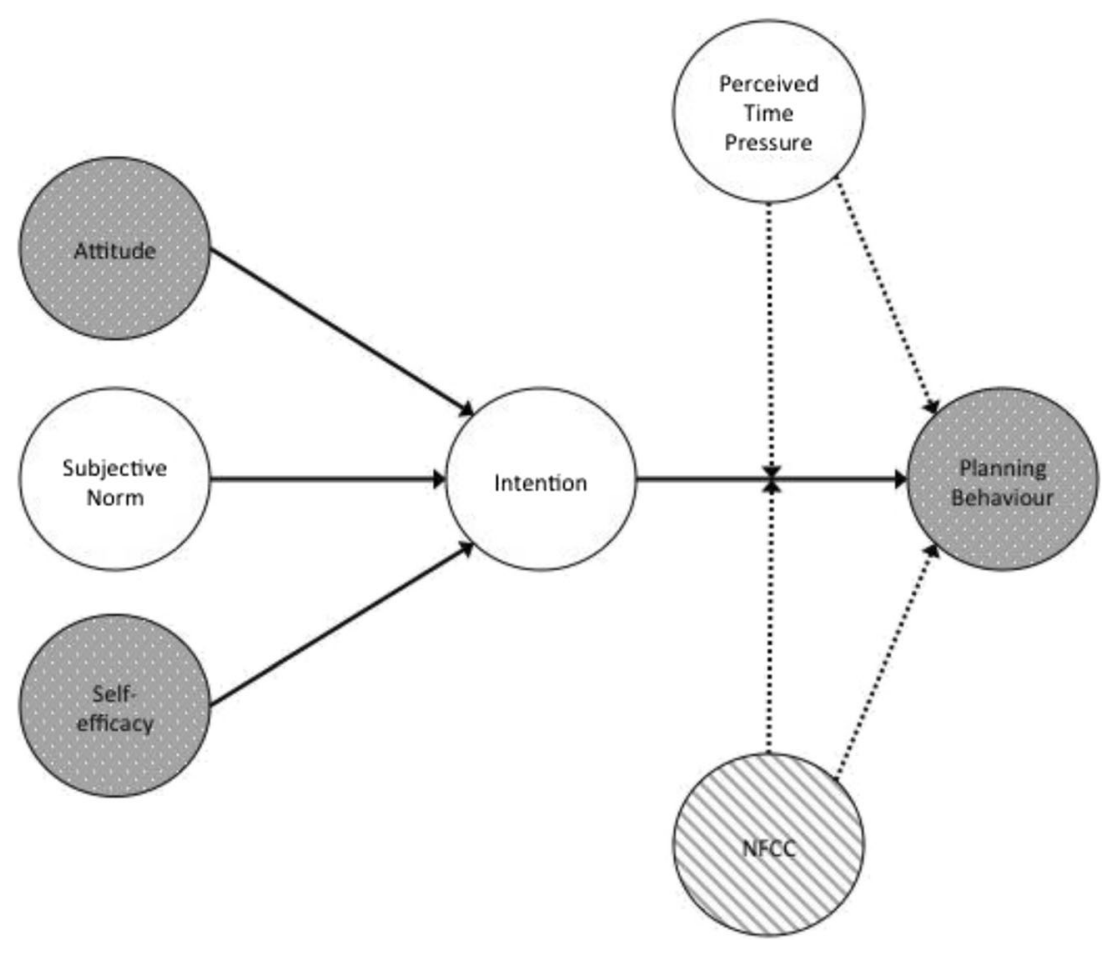


Also included in the questionnaire were questions relating to investigators' attitudes. First, questions concerning evaluation ahead of planning were asked (see Table 8 in Appendix 2, items APP1-2). The questionnaire additionally covered more specified aspects of evaluation (that is, necessity, effectiveness, efficiency, and usefulness of interview planning). The questionnaire also included questions concerning subjective norms (adapted from Fishbein and Ajzen 2010) that related to investigators' perceptions of external pressure from, say, peers or superiors (SN1-4). Self-efficacy was also included, which measured investigators' beliefs in their own interview planning skill (SE1-6).

Regarding investigators' motivation to undertake planning, intention (INT1-3 - see Table 8 in Appendix 2) was measured. NFCC was measured by a single indicator, while perceived time pressure involved five questions (modified from Teng et al. 2010 - see PTP1-5 in Table 8 in Appendix 2). Finally, the perceived level of planning interviews (PLPI) concerns investigators' recall of their planning experiences (PLPI1-6) during the preceding 2 months before their survey responses.

\section{Participants}

Korean financial crime investigators (FCIs) were selected as the sample participants, since they generally undertake investigations themselves from the outset of the case. Convenience sampling was adopted because of time and environmental limitations. However, as the research involved police stations in a similar law enforcement area, systemic error was expected to be small. No incentives were given to respondents.

Table 2 Harman's factor analysis

\begin{tabular}{|c|c|c|c|c|c|c|}
\hline \multirow[t]{2}{*}{ Component } & \multicolumn{3}{|c|}{ Initial eigenvalues } & \multicolumn{3}{|c|}{ Extraction of squared loadings } \\
\hline & Total & $\%$ variance & Cumulative $\%$ & Total & $\%$ variance & Cumulative $\%$ \\
\hline 1 & 10.117 & 33.725 & 33.725 & 10.117 & 33.725 & 33.725 \\
\hline 2 & 4.812 & 16.039 & 49.764 & 4.812 & 16.039 & 49.764 \\
\hline 3 & 3.037 & 10.124 & 59.889 & 3.037 & 10.124 & 59.889 \\
\hline 4 & 1.809 & 6.030 & 65.919 & 1.809 & 6.030 & 65.919 \\
\hline 5 & 1.110 & 3.701 & 69.619 & 1.110 & 3.701 & 69.619 \\
\hline 6 & 1.081 & 3.604 & 73.223 & 1.081 & 3.604 & 73.223 \\
\hline 7 & .789 & 2.628 & 75.851 & & & \\
\hline 8 & .728 & 2.427 & 78.279 & & & \\
\hline 9 & .706 & 2.353 & 80.632 & & & \\
\hline 10 & .646 & 2.153 & 82.785 & & & \\
\hline 11 & .600 & 1.998 & 84.784 & & & \\
\hline 12 & .518 & 1.726 & 86.510 & & & \\
\hline 13 & .449 & 1.497 & 88.007 & & & \\
\hline 14 & .433 & 1.444 & 89.450 & & & \\
\hline 15 & .382 & 1.272 & 90.722 & & & \\
\hline 16 & .355 & 1.184 & 91.906 & & & \\
\hline 17 & .316 & 1.054 & 92.960 & & & \\
\hline 18 & .292 & .974 & 93.935 & & & \\
\hline 19 & .256 & .853 & 94.788 & & & \\
\hline 20 & .235 & .783 & 95.571 & & & \\
\hline 21 & .213 & .712 & 96.283 & & & \\
\hline 22 & .186 & .621 & 96.904 & & & \\
\hline 23 & .178 & .595 & 97.498 & & & \\
\hline 24 & .168 & .560 & 98.058 & & & \\
\hline 25 & .135 & .451 & 98.509 & & & \\
\hline 26 & .108 & .360 & 98.869 & & & \\
\hline 27 & .097 & .323 & 99.192 & & & \\
\hline 28 & .094 & .312 & 99.504 & & & \\
\hline 29 & .077 & .256 & 99.761 & & & \\
\hline 30 & .072 & .239 & 100.000 & & & \\
\hline
\end{tabular}

Extraction method: principal component analysis 
Fig. 3 Redundancy analysis of attitude (ATT) indicators

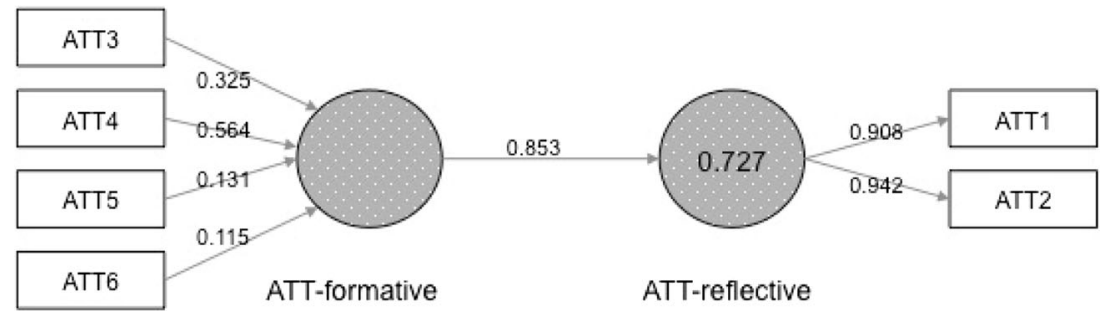

\section{Procedure}

During 2014, FCIs in eight police stations, located in Gyeonggi and Incheon areas of Korea, were selected as sources of possible participants. Each FCI team manager agreed to distribute the questionnaires to relevant FCI participants in their team, who were given a week to voluntarily complete the questionnaires. Participants were first instructed not to confer with their colleagues when completing the questionnaire and then place them. Once completed, they were each placed in sealed envelopes in a designated area for the team manager to collect, before their onward dispatch by the manager to the first author. Since the questionnaire contained no identifying information, the participants could be assured of their anonymity.

\section{Results}

\section{Demography of the Participants}

Of the approximate 125 distributed questionnaires, ${ }^{1} 95$ completed ones were received. Eighty percent $(n=76)$ of the respondents were male, and of the whole sample, all but two indicated that they had undergone PEACE training (however, despite this training, only 82 felt that had received training in planning). Even so, $94.74 \%(n=90)$ expressed a view that being trained to conduct planning was a necessity. Among the sample was one $(1.05 \%)$ junior ranked frontline officer, while $30.53 \%(n=29)$ were senior frontline police officers, $17.89 \%(n=17)$ were assistant inspectors, $42.11 \%(n=40)$ were inspectors, and $8.42 \%(n=8)$ were senior inspectors. Forty-eight respondents each possessed over 3 years of investigation experience, regardless of their rank (with 35 of these possessing over 5 years of experience). Thirty (31.58\%) respondents had been less than a year in post, while 17 respondents had been a FCI between 1 and 3 years.

\section{Analytical and Statistical Framework}

A second-generation statistical program of path modelling termed partial least squares (PLS-PM) was used for the data

\footnotetext{
${ }^{1}$ The exact number of questionnaires distributed is not known, owing to staff movements/absence of the FCIs in the eight stations, and this is an approximate figure.
}

analysis, being a form of structural equation modelling (SEM). The PLS-PM is especially well suited for the present study with its relatively small sample size. The PLS-PM method estimates parameters of both inner (structural) and outer (measurement) models. "Outer model" refers to the evaluation of the relationship between observable indicators and latent (or unobservable) variables, such as attitudes and perceptions, while "inner model" involves the evaluation of the latent (or hidden) variables.

We used SmartPLS 3.0 to analyse both the outer and inner models. PLS algorithms were calculated with all indicators of each latent variable, followed by bootstrapping in order to assess statistical significance. The analysis criteria were based on the default setting (i.e. 300 maximum iterations and 500 subsamples, where $p=0.05$ ). Three potentially problematic indicators loaded especially poorly on the latent variable in question and were therefore excluded from later analysis. Firstly, SN4 was removed since it showed low loading (i.e. 0.35). Secondly, PLPI5 (and PTP2) were both excluded because they did not significantly load onto the proposed latent factor.

The present study also investigated the potential for measurement error as a result of the chosen methodology (common method variance). The importance of testing this is evident as it can skew the results (Podsakoff et al. 2003). Common method bias was tested by two distinct approaches (see below) on how to address potential self-administered survey method biases. Harman's single factor test was conducted by undertaking an exploratory, un-rotated factor analysis of all the indicators with the exception of NFCC. This produced showed six distinct factors, with the largest one explaining $33.7 \%$ of the variance, as shown in Table 2. Secondly, as there was no correlation which exceeded 0.90 between the indicators, no common method bias was found. This indicates that such systematic measurement error will not threaten the validity of the results and conclusions of the present study (Podsakoff et al. 2003).

The analysis of the measurement (outer) and structural (inner) model was conducted simultaneously but is presented separately here for the ease of reading.

\section{Measurement Model (Outer Model)}

\section{Evaluation of the Formative Indicators}

Firstly, the formative measurement model was tested because this should be differentiated from reflective indicators (Chin 
2010). As we noted above, the aim of the measurement model is to establish the relationships between the observed variables (indicators) and the proposed latent factors. Following the initial indicator screening, multi-collinearity was checked for each of the formative indicators by the level of variance inflation factor (VIF). Next, a two-block model "redundancy analysis" was conducted to investigate the convergent validity of indicators. PLS bootstrapping was also conducted, and the indicators were considered significant at $p<0.05$. For the assessment, three new models for each formative construct were created for redundancy analysis to assess convergent validity and analysed by PLS.

The attitude construct model for redundancy analysis showed a high correlation of 0.85 between its indicators (see Fig. 3). However, the weightings of two indicators (i.e. ATT5 and ATT6) were found not significant $(p>0.05)$. Nevertheless, it was decided to still include them due to their absolute contribution to each latent variable (i.e. high loadings with significant level, see Table 3) and their conceptual meaning for this study. Next, multi-collinearity was checked for each of the indicators by the level of VIF. It was found that, as the VIF for all attitude indicators was below Lowry and Gaskin's (2014) threshold of rigour of 3.3 (see Table 3), multicollinearity did not exist. This result indicated that sufficient validation of attitude indicators was achieved.

The self-efficacy construct was then similarly tested. The path coefficient was 0.79 , argued as acceptable in such an exploratory study as the present one (see Fig. 4). Indicators
SE3 and SE5 showed relatively stronger weightings than SE4 and SE6 (both of which were non-significant). Nonetheless, the latter indicators were not excluded as all outer model loadings were significant $(p<0.01)$. The VIFs for all self-efficacy indicators were below the acceptable criterion of 10 (Lowry and Gaskin 2014).

Undergoing the same procedure, the PLPI construct was also similarly tested. The correlation between the PLPI indicators was 0.79 (see Fig. 5). As such, all formative indicators were found to be significant (see Table 3). Multi-collinearity was again not found (i.e. all indicators with VIF below 3.3).

\section{Evaluation of the Reflective Indicators}

To assess the reflective indicators, the constructs were analysed by performing a confirmatory factor analysis. As shown in Table 4, all indicators showed high loadings over 0.70 , except $\mathrm{SN} 1(0.67)$, which is acceptable, all being significant. Also, all composite reliabilities, used to assess internal consistency (being an alternative to Cronbach's alpha), were found to be over 0.70 (i.e. the reliability threshold).

To evaluate the convergent validity of the indicators, the average variance extracted (AVE) was examined (see Table 4), consistently finding values exceeding the threshold of 0.5 (Bagozzi and Yi 1988). Outer loadings of indicators on their latent construct were compared with the loadings of other indicators (see Table 5), concluding that the loadings had acceptable values (Lowry and Gaskin 2014). Each square root of
Table 3 Analysis result of indicators

\begin{tabular}{ccccccccc}
\hline Construct & Loadings & $p$ value & Weights & $T$-statistics & $p$ value & WIF & Path coefficients & $p$ value \\
\hline Attitude & & & & & & & & 0.000 \\
ATT1 & 0.908 & 0.000 & 0.479 & 31.637 & 0.000 & 2.041 & 0.853 & \\
ATT2 & 0.942 & 0.000 & 0.600 & 19.602 & 0.000 & 2.041 & & \\
ATT3 & 0.892 & 0.000 & 0.325 & 2.365 & 0.018 & 2.613 & \\
ATT4 & 0.951 & 0.000 & 0.564 & 3.758 & 0.000 & 2.626 & \\
ATT5 & 0.670 & 0.000 & 0.131 & 1.569 & 0.117 & 1.548 & \\
ATT6 & 0.741 & 0.000 & 0.115 & 1.115 & 0.265 & 1.874 & \\
Self-efficacy & & & & & & & \\
SE1 & 0.888 & 0.000 & 0.712 & 10.648 & 0.000 & 1.146 & 0.786 & \\
SE2 & 0.746 & 0.000 & 0.493 & 9.983 & 0.000 & 1.146 & \\
SE3 & 0.910 & 0.000 & 0.415 & 2.657 & 0.008 & 2.655 & \\
SE4 & 0.737 & 0.000 & 0.166 & 1.250 & 0.212 & 1.729 & \\
SE5 & 0.946 & 0.000 & 0.594 & 3.041 & 0.002 & 4.300 & \\
SE6 & 0.821 & 0.000 & -0.076 & 0.462 & 0.644 & 3.720 & \\
PLPI & & & & & & & \\
PLPI1 & 0.934 & 0.000 & 0.508 & 29.752 & 0.000 & 2.417 & 0.790 & \\
PLPI2 & 0.945 & 0.000 & 0.556 & 25.940 & 0.000 & 2.417 & \\
PLPI3 & 0.873 & 0.000 & 0.362 & 3.181 & 0.002 & 2.104 & \\
PLPI4 & 0.725 & 0.000 & 0.254 & 2.283 & 0.023 & 1.494 & \\
PLPI6 & 0.918 & 0.000 & 0.544 & 5.033 & 0.000 & 1.957 & \\
\hline PLP1 & & & & & \\
\end{tabular}

PLPI perceived level of planning interviews 
Fig. 4 Redundancy analysis of self-efficacy (SE) indicators

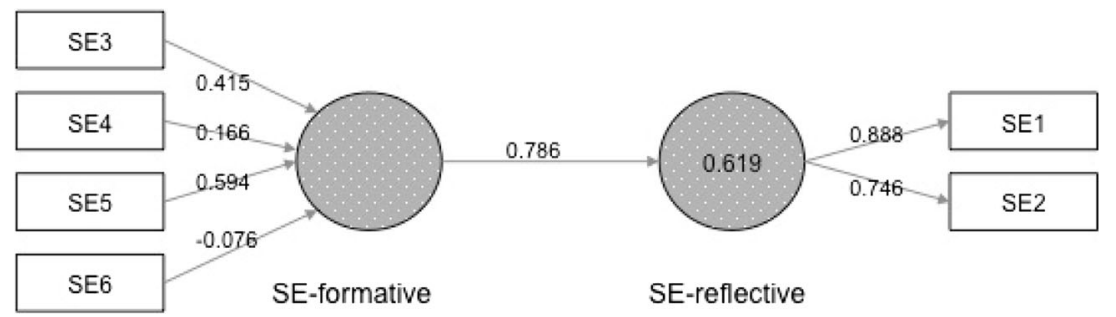

AVE of the latent variables was examined (see Table 6). All the relationships were stronger than those between the latent variables. This indicates that the constructs have good discriminant validity.

\section{Structural Model (Inner Model)}

Figure 6 shows the inner model results. As can be seen from this figure, three pathways were statistically significant $(p<0.05)$. The beta for the path between subjective norm and intention was 0.45 , while the corresponding figures between self-efficacy and intention and, in turn, between intention and PLPI were found to be beta $=0.41$ and beta $=0.80$, respectively. The $R^{2}$ of intention was 0.65 , and that of PLPI was $0.67(p<0.01)$. Attitude, subjective norm, and selfefficacy accounted for $65 \%$ of the variance in intention, while, in turn, intention accounted for $66.7 \%$ of the variance in PLPI. Not all paths between the latent variables were significant as can be seen from Table 7 .

Effect sizes were calculated, finding $f$ square for the relationships between (i) self-efficacy and intention to be 0.42 and (ii) subjective norm and intention to be 0.33 , while (iii) the effect size was 1.89 for intention on PLPI (where 0.40 values and above for $f$ are deemed strong, while medium-strength effect sizes lie between 0.25 to 0.49 for $f$ (see Gefen and Straub 2005).

Only attitude to intention and perceived time pressures to PLPI showed path coefficients at the level of $p<0.10$. In addition, the proposed moderating effect of perceived time pressures and NFCC between intention and PLPI was not significant (i.e. perceived time pressures interaction $=-0.07$ with $p=0.18$, NFCC interaction $=0.01$ with $p=0.61$ ).

\section{Discussion}

As previous research upon the planning phase of investigative interviews has mostly examined only the level of planning, the present study set out to examine an area yet to be explored, that is, the possible reasons associated with investigators' decision-making as whether or not to plan. As such, the current study adds to the increasing and expanding literature based on investigative interviewing.

The present exploratory study provided empirical understanding of factors proposed to be associated with investigators' planning interviews with suspects. Firstly, it was hypothesised that interview planning would be positively associated by interviewers' attitudes towards undertaking the task. Among the antecedent factors of the theory of planned behaviour, attitude was found to have a weak relationship with planning intentions. The findings indicated that regardless of their rank, career, or gender, most participants in our survey provided a positive evaluation of planning. Contrary to assumptions, however, investigators' attitudes were not found to be associated with their interview preparations. This could be so due to the inconsistency between attitude and actual behaviour (Ajzen and Fishbein 2005). The relative importance of each indicator of investigators' attitudes towards planning varied. Perceptions relating to the usefulness of planning and those concerning efficiency were found to be more important than indicators pertaining to perceived necessity of planning and its effectiveness, which were found to be much less influential.

As hypothesised, intention to plan was strongly associated with PLPI. This finding suggests that police investigators who have more intention to plan would, in turn, engage in more planning than those who have less. This supports the belief that intention is probably most strongly associated with the prediction of planning behaviour (Ajzen 1991; Armitage and Conner 2001). It is, however, acknowledged that this finding could possibly stem from one of the study's methodological limitations, since PLPI was measured by surveying participants' perceptions rather than their actual practice. Investigators may also have considered that since they believe that they undertake much planning, their intentions must be
Fig. 5 Redundancy analysis of perceived level of planning interviews (PLPI) indicators

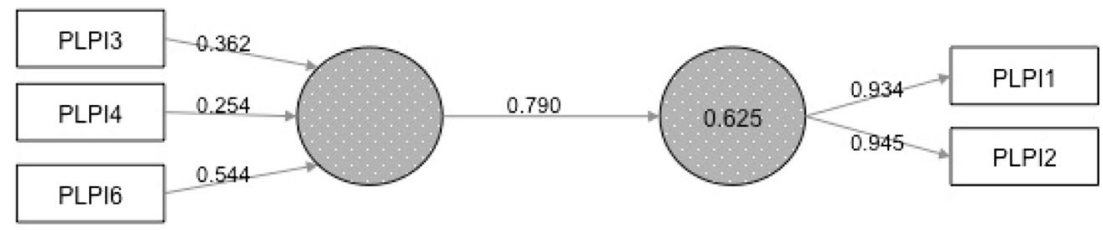

PLPI-formative
PLPI-reflective 
accordingly strong. If that is indeed the case, it might be the perceived level of planning that is prompting the intention, and not the reverse. As such, it is recommended that future research into this area is undertaken by other methods, such as observational or "think aloud" methodologies.

In line with the next hypothesis, the correlations suggested a strong relationship between subjective norm and planning intentions. Such a relationship is perhaps not surprising since such normative beliefs (or organisational culture) have repeatedly been considered an important factor in criminal investigations (Chan 2007; Crank 2010; Gottschalk 2007). The latter is likely related to the specific and unique working culture that dominates much police practice, which is mostly learned from "on the job" experience (Tong et al. 2009).

Interestingly, the variable of whether fellow investigators tended to investigate first before interviewing did not load onto the subjective norm construct. This was not unexpected because the content of the question is quite different from that of the other subjective norm indicators contained in the questionnaire, and consequently, the question may have been unfamiliar to participants. At the same time, two thirds of participants provided a rating for this question of less than the midpoint of the scale. As such, it might be assumed that the investigators" perceptions concerning the culture of "investigate after interviewing" are relatively high. This finding would reflect inconsistency with the fundamental aims of investigative interviewing (i.e. where, whenever possible, interviews with suspects should be undertaken later in the investigative process). Considering that the survey involved financial crime investigators, this is a finding of some concern, if found to be one that plays out in practice. Such investigators have greater opportunity to defer interviews until after a comprehensive investigation has been completed, and fulsome evidence painstakingly gathered, than say, homicide or terrorism

Table 4 Results summary for outer models

\begin{tabular}{lllll}
\hline Construct & Loadings & $\begin{array}{l}p \\
\text { value }\end{array}$ & $\begin{array}{l}\text { Composite } \\
\text { reliability }\end{array}$ & AVE \\
\hline INT & & & & \\
INT1 & 0.864 & 0.000 & 0.909 & 0.770 \\
INT2 & 0.886 & 0.000 & & \\
INT3 & 0.883 & 0.000 & & 0.738 \\
PTP & & & & \\
PTP1 & 0.838 & 0.029 & 0.919 & \\
PTP3 & 0.866 & 0.036 & & 0.634 \\
PTP4 & 0.877 & 0.015 & & \\
PTP5 & 0.856 & 0.012 & & \\
SN & & & & \\
SN1 & 0.674 & 0.000 & 0.837 & \\
SN2 & 0.847 & 0.000 & & \\
SN3 & 0.854 & 0.000 & & \\
\hline
\end{tabular}

$I N T$ intention, $P T P$ perceived time pressure, $S N$ subjective norm
Table 5 Cross loading of reflective models

\begin{tabular}{lrrr}
\hline & \multicolumn{1}{l}{ INT } & \multicolumn{1}{l}{ PTP } & \multicolumn{1}{l}{ SN } \\
\hline INT1 & 0.864 & 0.038 & 0.565 \\
INT2 & 0.886 & 0.059 & 0.637 \\
INT3 & 0.883 & -0.199 & 0.634 \\
PTP1 & 0.009 & 0.838 & 0.052 \\
PTP3 & 0.050 & 0.866 & 0.111 \\
PTP4 & -0.112 & 0.877 & -0.068 \\
PTP5 & -0.041 & 0.856 & 0.027 \\
SN1 & 0.399 & -0.110 & 0.674 \\
SN2 & 0.597 & -0.081 & 0.847 \\
SN3 & 0.639 & 0.167 & 0.854 \\
\hline
\end{tabular}

INT intention, PTP perceived time pressure, $S N$ subjective norm

detectives (where matters of public protection from further harm are more likely to prompt both earlier arrest and interview of a suspect, before opportunity has occurred to collect much evidence).

Self-efficacy was found to have a strong relationship, as hypothesised, with both planning intention and PLPI. Indeed, self-efficacy was found to have a stronger association with intention than subjective norm. A possible explanation might involve the cognitively demanding activity associated with the planning of interviews. Prior research has found selfefficacy to have a significant relationship with various cognitive tasks (e.g. Celuch et al. 2010; Cervone and Peake 1986; Conner and Armitage 1998; Pajares and Kranzler 1995; Pajares and Schunk 2001). Self-efficacy has also been found to be associated with employee motivation and effort when learning difficult tasks (Lunenberg 2011). Walsh et al. (2017) found, in their study of investigators, a self-confidence about own interviewing ability, which, in turn, was found consistently inferior to that objectively assessed.

Of the examined self-efficacy indicators, that of "organising questions" was found to be of highest importance to investigators in their planning, while other indicators of "predicting suspects' defences", "knowing topics to ask", and "knowing points to prove" were found to be much less important. The latter three interviewing tasks are, however, considered to be critical when planning interviews (Shepherd and Griffiths 2013; Walsh and Bull 2010). As such, it is a matter of concern that investigators feel that these

Table 6 Discriminant validity by the square root of AVE

\begin{tabular}{llrrr}
\hline Construct & AVE & \multicolumn{1}{l}{ INT } & PTP & SN \\
\hline INT & 0.770 & 0.878 & & \\
PTP & 0.738 & -0.050 & 0.859 & \\
SN & 0.634 & 0.700 & 0.011 & 0.796 \\
\hline
\end{tabular}

$I N T$ intention, PTP perceived time pressure, $S N$ subjective norm 
Fig. 6 PLS results for interview planning factor relation. $P T P$ perceived time pressures, $A T T$ attitudes, $S N$ subjective norms, INT intention, PLPI perceived level of planning interviews, $S E$ self-efficacy, $N F C C$ need for cognitive closure
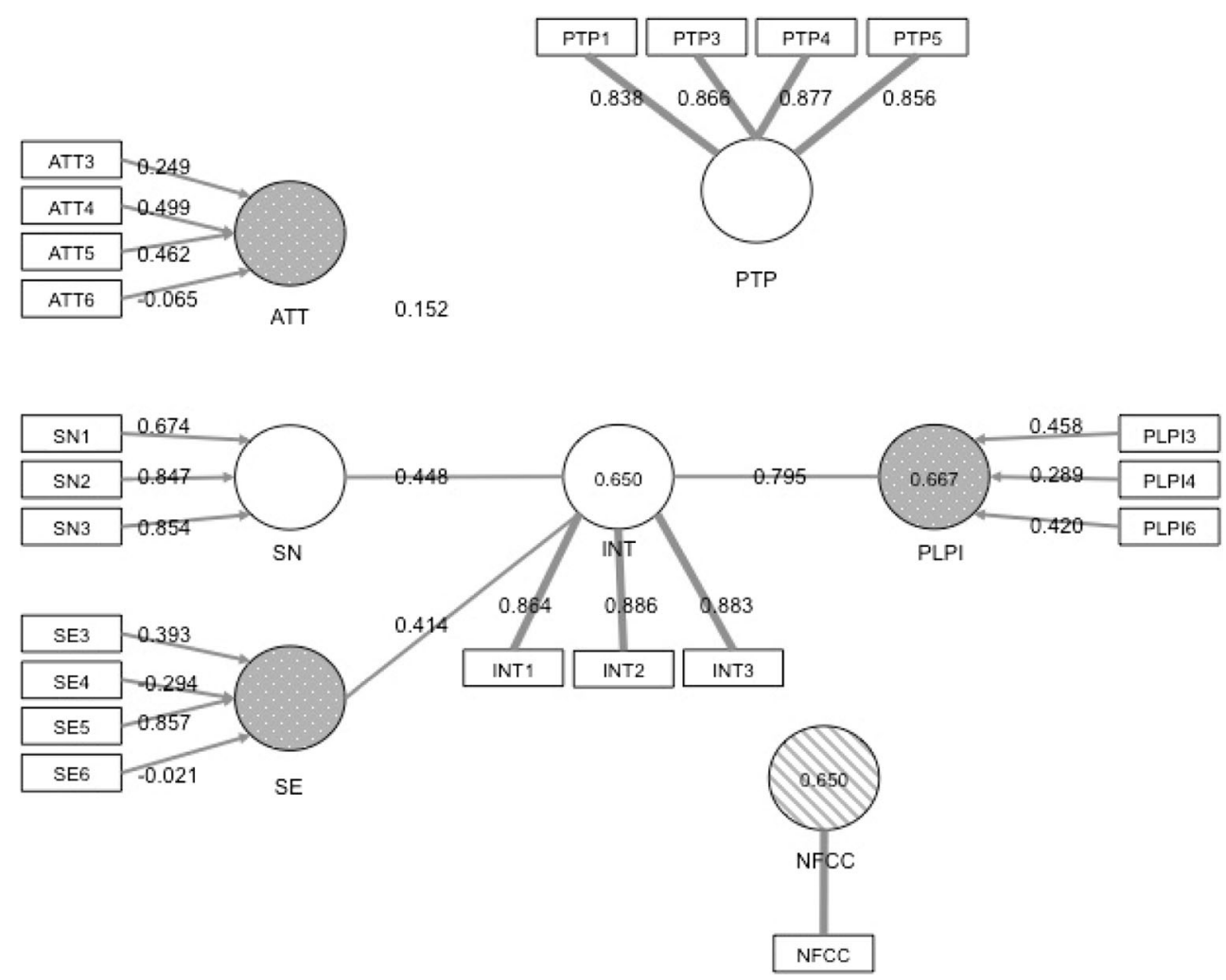

activities merit less attention. Thus, this finding suggests that police investigators who have more intention to plan would, in turn, engage in more planning than those who have less. This supports the belief that intention is probably most strongly associated with the prediction of planning behaviour (Ajzen 1991; Armitage and Conner 2001).

Perceived time pressures and NFCC, somewhat counterintuitively, were found to have a minimal correlation with PLPI. Participants apparently felt little time pressure for handling their cases, a finding that is inconsistent with prior research (Baldwin 1993; Cherryman and Bull 2001; Walsh and Milne 2007,2008). This finding might be related to the previously mentioned speculation that financial crime investigators are more likely to be able to have greater opportunity to thoroughly investigate before interviewing (and thus, in principle at least, possess greater time for planning). However, it may be that time pressure, when perceived to be moderate, may act as a stimulant for planning (Baer and Oldham 2006; Freedman and Edwards 1988; Janssen 2001).

The findings of the present study suggest that law enforcement agencies may well need to enhance the importance of interview planning for officers trained in the PEACE model
Table 7 Summary of path coefficients and significance levels

\begin{tabular}{lccl}
\hline Hypothesis & Path coefficients & T-statistics & Results \\
\hline Expected positive relationships & & & \\
$\quad$ Attitude $\rightarrow$ INT & 0.152 & 1.653 & Not supported* \\
$\mathrm{SN} \rightarrow$ INT & 0.448 & 4.553 & Supported** \\
$\mathrm{Self}-\mathrm{efficacy} \rightarrow \mathrm{INT}$ & 0.414 & 5.019 & Supported** \\
$\mathrm{INT} \rightarrow$ PLPI & 0.795 & 16.133 & Supported** \\
Expected negative relationships & & & \\
NFCC $\rightarrow$ PLPI & 0.085 & 1.227 & Not supported* \\
Moderation of "NFCC" between "INT" and "PLPI" & 0.007 & 0.508 & Not supported* \\
PTP $\rightarrow$ PLPI & -0.144 & 1.683 & Not supported* \\
Moderation of "PTP" between "INT" and "PLPI" & -0.074 & 1.346 & Not supported* \\
\hline
\end{tabular}

$I N T$ intention, $S N$ subjective norm, NFCC need for cognitive closure, PLPI perceived level of planning interviews, $P T P$ perceived time pressure

$* p>0.01 ; * * p<0.001$ 
(through, say, good supervision following such training). While planning is a fundamental part of the PEACE model, studies suggest that it is a task to which officers rarely attend (Walsh and Bull 2011; Walsh and Milne 2007). Further, studies of interviews conducted in the field suggest that planning is mediocre in practice, with thorough and skilled planning rarely having taken place (Clarke and Milne 2001; Walsh and Bull 2010, 2012). Such studies have also noted the positive association between planning skills and the recommended PEACE interview outcomes of obtaining extensive accounts from suspects, underlining the importance of planning. Indeed, Griffiths (2008) found that officers' planning skills faded over time after training, also noting that training alone (no matter how good) is insufficient in itself to ensure skills are maintained.

Walsh and Bull (2010) found some interviews in their sample (also of fraud investigators) were being conducted before an investigation had fully taken place, noting that such interviews were of a "fishing trip" characteristic. They had also rated these interviews, without exception, as the most poor in terms of planning skills (and likewise, least associated with the gaining of comprehensive accounts). Fraud investigators invariably have the luxury of being able to fully conduct a thorough investigation before any interview with identified suspects (compared, say, to violent crimes, where public safety issues may mean that an early arrest and interview of a suspect might be required before a thorough investigation has been allowed to take place). The findings from the present study suggest that occupational culture is associated with investigators' decisions as to whether or not to plan. As such, if an "interview before (fully) investigating" occupational culture exists, wherever possible, such a maxim should be changed to "interview after (fully) investigating".

Furthermore, current training should address both investigators' motivation to plan, as well as their capabilities of accurately assessing their own performance, since the present study found that self-efficacy is critically important to planning intent. Griffiths (2008) found that planning is a complex task. However, investigators have been found to possess little self-awareness of how poor were their own planning skills (Walsh et al. 2017). Griffiths and Walsh (submitted) found that more accurate self-awareness was only apparent when investigators exercised skilled reflection. Additionally, training for interview planning should emphasise the dangers of planning inflexibly, when considering the dynamic nature of groundwork.

\section{Study Limitations}

The present study, as with all studies, possesses limitations. First, it used a self-administered questionnaire, which could be affected by various biases (e.g. consistency motif, social desirability, leniency bias, and genuine misremembering). Second, the findings may not be fully generalizable since it was confined to FCIs operating in South Korea. Third, there may also be generalisability issues relating to the fact that more than two thirds of respondents were quite senior officers, who may not regularly conduct interviews. On the other hand, almost a third stated that they had less than a year of professional experience. Nevertheless, over a third of respondents possessed more than 5 years of experience and it would be reasonably expected that their views emerged from the vantage point of their having conducted many interviews. When turning to investigators' individual cognitive dispositions while NFCC was not found to significantly relate to PLPI, we speculate whether this finding might stem from the limitation to assess such cognitive disposition through abridged self-administered questionnaires. Indeed, other research (which also employed similar limited predictors) also found non-significant outcomes (O’Neill 2011). Ask and Granhag (2005) also found that NFCC did not significantly affect bias in investigative decision-making. As these authors recommend, a more valid test of this disposition might be needed.

\section{Summary}

Overall, this exploratory research has provided empirical understanding concerning investigators' interview planning attitudes. Using the framework of a well-known theory of human behaviour, the study did find factors apparently associated with investigators' planning. The working environment norms of police investigators were found to be strongly associated with planning intentions. Also, investigators' self-efficacy of their planning-related capabilities was also found to have a strong relationship with intention and perceived level of planning. Above all, intention to plan was found to have a powerful association with interview planning. Contrary to common beliefs regarding possible reasons for poor planning (i.e. time pressure), the present study found that investigators' own perception of their planning skills and their subjective norms appear to potentially play a more substantial role. Thus, necessary measures and academic research undertaken to improve any lack of planning might be less focused on the time pressure issue.

However, further research is required to understand the actual interview planning practice of police investigators, to establish how to enhance planning practice (e.g. by using think aloud methodologies). Recent research on developing effective strategies when interviewing suspects has emphasised the importance of developing an interview strategy (Dando et al. 2015; Hartwig et al. 2005a, b, 2006, 2007; van der Sleen 2009; Walsh and Bull 2015). The necessity to 
plan interviews should not be overlooked, being as important as other investigative tasks. Better-prepared interviewers will be better placed to challenge capricious and evasive suspects. Additionally, better-prepared investigators tend more often to establish the reliability of given accounts (Walsh and Bull 2010). Finally, interview planning is not a discrete task (Walsh et al. 2012). As such, further research is essential to examine all pre-interview groundwork (such as investigative decision-making) to help contribute to effective investigative interviewing.

Funding Information No external funding was associated with this research.

\section{Compliance with Ethical Standards}

Ethical Statement As stated in the article, research ethics was provided by the home university, having successfully proceeded through the relevant ethics committee (who ensured that all survey respondents were advised of their informed and voluntary consent before their participation).

Conflict of Interest The authors declare that they have no conflict of interest.

\section{Appendix 1. Survey questionnaire (note: the original questionnaire was in the Korean language but has been translated here for the purposes of publication)}

This study intends to understand the relationship of possible factors which influence the investigator's planning behaviour prior to suspect interviewing. This questionnaire was formulated to discover investigator's perception, which relates to actual planning behaviour and other internal or external factors which could affect the planning activity of police investigators. Your participation is highly expected to contribute to the development of police investigation. The researcher appreciates your participation in this study. Please read each question carefully and answer it to the best of your ability. There are no correct or incorrect responses, so please answer those questions following your genuine opinion. We guarantee the participant's anonymity.

$<$ What is your gender? $>$

- Male/Female

$<$ What is your rank? $>$

- Policeman/Senior Policeman/Assistant Inspector/ Inspector/Senior Inspector

$<$ How long have you been working in the current investigation position (i.e. investigative interviewing)?>

- 1 year/ $1-2$ years $/ 2-3$ years $/ 3-5$ years/over 5 years

The below questionnaire is intended to ask your perception on the planning suspect interviewing-related issue. Please answer with your genuine opinion, as there is no proper answer.
This used the seven-point Likert scale from 1, which means "Strongly disagree", to 7, which is "Strongly agree". Although the question looks like repeating, every question has its own meaning.

\begin{tabular}{rrr} 
No. Question & $\begin{array}{r}\text { Absolutely } \\
\text { disagree }\end{array}$ & $\begin{array}{c}\text { Absolutel } \\
\text { agree }\end{array}$ \\
\hline
\end{tabular}

1 I think planning suspect interviewing is $1-2-3-4-5-6-7$ desirable for successful interviewing outcome.

2 I don't think my peer investigators 1 - 2 - 3 - 4 - 5 - 6 - 7 expect me to do planning interviewing for successful interviewing outcome.

3 I think I am good at planning 1 - 2-3-4 - 5-6 - 7 interviewing.

4 I intend to do planning interviewing 1 - 2-3-4-5-6-7 prior to suspect interviewing.

5 I think I often feel time pressure to finish 1 - 2 - 3 - 4 - 5 - 6 - 7 the assigned criminal case.

6 During the last two months, I usually $1-2-3-4-5-6-7$ have made specific interview plan prior to suspect interviewing.

7 I think planning suspect interviewing is $1-2-3-4-5-6-7$ good for successful interviewing outcome.

8 I think planning suspect interviewing is $1-2-3-4-5-6-7$ necessary for successful interviewing outcome (or, obtaining anticipated outcome).

9 I think my team manager expect me to $1-2-3-4-5-6-7$ do planning interviewing for successful interviewing outcome.

10 I don't think I have enough competences 1 - 2 - 3 - 4 - 5 - 6 - 7 in planning interviewing.

11 I will try to do planning interviewing $1-2-3-4-5-6-7$ prior to suspect interviewing.

12 I think I often feel in a hurry to finish the 1 - 2-3 - 4 - 5 - 6 - 7 assigned criminal case.

13 During the last two months, I usually $1-2-3-4-5-6-7$ have planned for suspect interviewing.

14 I think planning suspect interviewing is $1-2-3-4-5-6-7$ useful for successful interviewing outcome.

15 I think my peer investigators are trying 1 - 2 - 3 - 4 - 5 - 6 - 7 to do planning before interviewing.

16 I think I am good at figuring out $1-2-3-4-5-6-7$ important topics which should be dealt in interviewing prior to actual interviewing.

17 I am well motivated to do planning 1 - 2 - 3 - 4 - 5 - 6 - 7 interviewing prior to suspect interviewing.

18 I think I often feel very busy in dealing 1 - 2 - 3 - 4 - 5 - 6 - 7 with the assigned criminal case.

19 I don't think I often feel heavy time $1-2-3-4-5-6-7$ pressure to finish the assigned criminal case.

20 During the last two months, I usually $1-2-3-4-5-6-7$ have set some sort of interview goal which I must accomplish prior to suspect interviewing. 
21 During the last two months, I usually have made a list of points to prove prior to suspect interviewing.

22 I don't think planning suspect interviewing is efficient for intended interviewing outcome.

23 I think my peer investigators do interviewing first rather than investigating first.

24 I think I am confident of predicting suspect's defence before interviewing suspect.

25 I think I often have limited time to handle my case.

26 During the last two months, I usually have contemplated the possible defence of suspect prior to suspect interviewing.

27 I think planning suspect interviewing is 1 - 2 - 3 - 4 - 5 - 6 - 7 effective for successful interviewing outcome.

28 I think I have good ability to organise sequence of questioning.

29 During the last two months, I usually have made plan for how to ask questions in what order prior to suspect interviewing.

30 I think I have good competences in recognising points to prove before interviewing suspect.

Next, the questionnaire measures your own cognitive disposition. Please answer in the same way as before.

\begin{tabular}{llc}
\hline No. Question & $\begin{array}{c}\text { Absolutely } \\
\text { disagree }\end{array}$ & $\begin{array}{c}\text { Absolutely } \\
\text { agree }\end{array}$ \\
\hline 1 & I don't like situations that are uncertain. & $1-2-3-4-5-6$ \\
2 & $\begin{array}{c}\text { I like questions which could be } \\
\text { answered in many different ways. }\end{array}$ & $1-2-3-4-5-6$ \\
3 & $\begin{array}{c}\text { I find that a well-ordered life with regu- } \\
\text { lar hours suits my temperament. }\end{array}$ \\
4 & $1-2-3-4-5-6$ \\
& $1-2-3-4-5-6$ \\
\hline
\end{tabular}

I feel uncomfortable when I don't understand the reason why an event occurred in my life.

5 I feel uncomfortable when I don't 1 - 2-3-4-5-6 understand the reason why an event occurred in my life.

6 I don't like to go into a situation without 1 - 2 - 3 - 4 - 5 - 6 knowing what I can expect from it.

7 When I have made a decision, I feel 1 - 2-3-4 - 5- 6 relieved.

8 When I am confronted with a problem, 1 - 2 - 3 - 4 - 5 - 6 I'm dying to reach a solution very quickly.

9 I would quickly become impatient and 1 - 2-3-4 - 5 - 6 irritated if I would not find a solution to a problem immediately.

10 I like to be with people who are capable 1 - 2 - 3 - 4 - 5 - 6 of unexpected actions.

11 I dislike it when a person's statement 1 - 2-3-4-5-6 could mean many different things.

12 I find that establishing a consistent $1-2-3-4-5-6$ routine enables me to enjoy life more.

13 I enjoy having a clear and structured 1-2-3-4-5-6 mode of life.

14 I do not usually consult many different 1 - 2-3-4-5-6 opinions before forming my own view.

15 I like unpredictable situations. 1 - 2-3-4 - 5- 6

$<$ Have you ever had a training which is for 'planning suspect interviewing'?>

- Yes/No

$<$ Do you think that there is a need to training for "planning suspect interviewing'?>

- Yes/No

$<$ Have you been taught about PEACE model of England and Wales?>

- Yes/No

Thank you for your participation.

\section{Appendix 2}

Table 8 Explanation of measurement items

\begin{tabular}{|c|c|c|c|c|}
\hline Construct & Operationalised definition & Label no. & Items & $\begin{array}{l}\text { Type of } \\
\text { construct }\end{array}$ \\
\hline \multirow[t]{2}{*}{ Attitude (ATT) } & \multirow[t]{2}{*}{$\begin{array}{l}\text { Investigator's evaluative } \\
\text { perception on the planning } \\
\text { behaviour prior to suspect } \\
\text { interviewing }\end{array}$} & ATT1 & $\begin{array}{l}\text { I think planning suspect interviewing is } \\
\text { desirable for a successful interviewing } \\
\text { outcome. } \\
\text { I think planning suspect interviewing } \\
\text { is good for a successful interviewing } \\
\text { outcome. }\end{array}$ & Reflective \\
\hline & & ATT3 & $\begin{array}{l}\text { I think planning suspect interviewing is } \\
\text { necessary for a successful interviewing } \\
\text { outcome (or, obtaining intended outcome). }\end{array}$ & Formative \\
\hline
\end{tabular}


Table 8 (continued)

\begin{tabular}{|c|c|c|c|c|}
\hline Construct & Operationalised definition & Label no. & Items & $\begin{array}{l}\text { Type of } \\
\text { construct }\end{array}$ \\
\hline & & ATT4 & $\begin{array}{l}\text { I think planning suspect interviewing } \\
\text { is useful for a successful interviewing } \\
\text { outcome. }\end{array}$ & \\
\hline & & ATT5 & $\begin{array}{l}\text { I think planning suspect interviewing is } \\
\text { efficient for a successful interviewing } \\
\text { outcome. }\end{array}$ & \\
\hline & & ATT6 & $\begin{array}{l}\text { I think planning suspect interviewing } \\
\text { is effective for intended interviewing } \\
\text { outcome. }\end{array}$ & \\
\hline \multirow[t]{4}{*}{ Subjective norm (SN) } & \multirow[t]{4}{*}{$\begin{array}{l}\text { Investigator's perceived external } \\
\text { pressure (norm) on the planning } \\
\text { behaviour prior to suspect } \\
\text { interviewing }\end{array}$} & SN1 & $\begin{array}{l}\text { I think my peer investigators expect } \\
\text { me to do planning interviewing } \\
\text { for a successful interviewing } \\
\text { outcome. }\end{array}$ & Reflective \\
\hline & & SN2 & $\begin{array}{l}\text { I think my team manager expect me } \\
\text { to do planning interviewing for a } \\
\text { successful interviewing outcome. }\end{array}$ & \\
\hline & & $\mathrm{SN} 3$ & $\begin{array}{l}\text { I think my peer investigators are } \\
\text { trying to do planning before } \\
\text { interviewing. }\end{array}$ & \\
\hline & & SN4 & $\begin{array}{l}\text { I think my peer investigators do } \\
\text { interviewing first rather than } \\
\text { investigating first. }\end{array}$ & \\
\hline \multirow[t]{6}{*}{ Self-efficacy (SE) } & \multirow{6}{*}{$\begin{array}{l}\text { Investigator's perceived } \\
\text { competency in planning } \\
\text { interviewing prior to suspect } \\
\text { interviewing }\end{array}$} & SE1 & $\begin{array}{l}\text { I think I am good at planning } \\
\text { interviewing. }\end{array}$ & Reflective \\
\hline & & SE2 & $\begin{array}{l}\text { I think I have enough competences } \\
\text { in planning interviewing. }\end{array}$ & \\
\hline & & SE3 & $\begin{array}{l}\text { I think I am good at figuring out } \\
\text { important topics which should be } \\
\text { dealt in interviewing prior to } \\
\text { actual interviewing. }\end{array}$ & Formative \\
\hline & & SE4 & $\begin{array}{l}\text { I think I am confident of predicting } \\
\text { suspect's defence before } \\
\text { interviewing suspect. }\end{array}$ & \\
\hline & & SE5 & $\begin{array}{l}\text { I think I have a good ability to organise } \\
\text { sequence of questioning. }\end{array}$ & \\
\hline & & SE6 & $\begin{array}{l}\text { I think I have good competences in } \\
\text { recognising points to prove before } \\
\text { interviewing suspect. }\end{array}$ & \\
\hline \multirow[t]{3}{*}{ Intention (INT) } & \multirow{3}{*}{$\begin{array}{l}\text { Investigator's desire to do } \\
\text { planning interviewing prior } \\
\text { to suspect interviewing }\end{array}$} & INT1 & $\begin{array}{l}\text { I intend to do planning interviewing } \\
\text { prior to suspect interviewing. }\end{array}$ & Reflective \\
\hline & & INT2 & $\begin{array}{l}\text { I will try to do planning interviewing } \\
\text { prior to suspect interviewing. }\end{array}$ & \\
\hline & & INT3 & $\begin{array}{l}\text { I am well motivated to do planning } \\
\text { interviewing prior to suspect } \\
\text { interviewing. }\end{array}$ & \\
\hline $\begin{array}{l}\text { Need for cognitive } \\
\text { closure (NFCC) }\end{array}$ & Investigator's individual NFCC & & & $\begin{array}{l}\text { Single item (actually, } \\
\text { summational item) }\end{array}$ \\
\hline \multirow[t]{4}{*}{$\begin{array}{l}\text { Perceived time } \\
\text { pressure (PTP) }\end{array}$} & \multirow{4}{*}{$\begin{array}{l}\text { Investigator's perception on the } \\
\text { degree of how much time } \\
\text { pressure they have in handling } \\
\text { their assigned investigation case }\end{array}$} & PTP1 & $\begin{array}{l}\text { I think I often feel time pressure to } \\
\text { finish the assigned criminal case. }\end{array}$ & \multirow[t]{4}{*}{ Reflective } \\
\hline & & PTP2 & $\begin{array}{l}\text { I think I often feel in a hurry to } \\
\text { finish the assigned criminal case. }\end{array}$ & \\
\hline & & PTP3 & $\begin{array}{l}\text { I think I often feel very busy in } \\
\text { dealing with the assigned } \\
\text { criminal case. }\end{array}$ & \\
\hline & & PTP4 & $\begin{array}{l}\text { I think I often feel heavy time pressure } \\
\text { to finish the assigned criminal case. }\end{array}$ & \\
\hline
\end{tabular}


Table 8 (continued)

\begin{tabular}{|c|c|c|c|c|}
\hline Construct & Operationalised definition & Label no. & Items & $\begin{array}{l}\text { Type of } \\
\text { construct }\end{array}$ \\
\hline & & PTP5 & $\begin{array}{l}\text { I think I often have limited time to } \\
\text { handle my case. }\end{array}$ & \\
\hline \multirow[t]{6}{*}{$\begin{array}{l}\text { Perceived level } \\
\text { of planning } \\
\text { interviews (PLPI) }\end{array}$} & \multirow[t]{6}{*}{$\begin{array}{l}\text { Investigator's perception on } \\
\text { how much they did planning } \\
\text { interview during last } 2 \text { months }\end{array}$} & PLPI1 & $\begin{array}{l}\text { During the last two months, I usually } \\
\text { have made specific interview plan } \\
\text { prior to suspect interviewing. }\end{array}$ & Reflective \\
\hline & & PLPI2 & $\begin{array}{l}\text { During the last two months, I usually } \\
\text { have planned for suspect interviewing. }\end{array}$ & \\
\hline & & PLPI3 & $\begin{array}{l}\text { During the last two months, I usually } \\
\text { have set some sort of interview } \\
\text { goal which I must accomplish } \\
\text { prior to suspect interviewing. }\end{array}$ & Formative \\
\hline & & PLPI4 & $\begin{array}{l}\text { During the last two months, I usually } \\
\text { have made a list of points to prove } \\
\text { prior to suspect interviewing. }\end{array}$ & \\
\hline & & PLPI5 & $\begin{array}{l}\text { During the last two months, I usually } \\
\text { have contemplated the possible } \\
\text { defence of suspect prior to suspect } \\
\text { interviewing. }\end{array}$ & \\
\hline & & PLPI6 & $\begin{array}{l}\text { During the last two months, I usually } \\
\text { have made plan for how to ask } \\
\text { questions in what order prior to } \\
\text { suspect interviewing. }\end{array}$ & \\
\hline
\end{tabular}

Open Access This article is distributed under the terms of the Creative Commons Attribution 4.0 International License (http:// creativecommons.org/licenses/by/4.0/), which permits unrestricted use, distribution, and reproduction in any medium, provided you give appropriate credit to the original author(s) and the source, provide a link to the Creative Commons license, and indicate if changes were made.

\section{References}

Ajzen I (1991) The theory of planned behavior. Organ Behav Hum Decis Process 50(2):179-211. https://doi.org/10.1016/0749-5978(91) 90020-t

Ajzen I (2006) The theory of planned behavior: constructing a Theory of Planned Behaviour questionnaire. Available: http://people.umass. edu/aizen/pdf/tpb.measurement.pdf [Accessed: 14 Jan 2014]

Ajzen I, Fishbein M (2000) Attitudes and attitude-behavior relation: reasoned and automatic processes. In: Stroebe W, Hewstone M (eds) European review of social psychology. Wiley, Chichester, pp 1-33. https://doi.org/10.1080/14792779943000116

Ajzen I, Fishbein M (2005) The influence of attitudes on behavior. In: Albarracín D, Johnson BT, Zanna MP (eds) The handbook of attitudes. Erlbaum, Mahwah, pp 173-221

Armitage CJ, Conner M (2001) Efficacy of the theory of planned behaviour: a meta-analytic review. Br J Soc Psychol 40(4):471-499. https://doi.org/10.1348/014466601164939

Ask K, Granhag PA (2005) Motivational sources of confirmation bias in criminal investigations: the need for cognitive closure. J Investig Psychol Offender Profiling 2(1):43-63. https://doi.org/10.1002/jip.19

Baer M, Oldham GR (2006) The curvilinear relation between experienced creative time pressure and creativity: moderating effects of openness to experience and support for creativity. J Appl Psychol 91(4):963-970. https://doi.org/10.1037/0021-9010.91.4.963

Bagozzi RP, Yi Y (1988) On the evaluation of structural equation models. J Acad Mark Sci 16(1):74-94. https://doi.org/10.1007/bf02723327

Baldwin J (1993) Police interview techniques: establishing truth or proof? Br J Criminol 33(3):325-352. https://doi.org/10.1093/ oxfordjournals.bjc.a048329

Bandura A (1982) Self-efficacy mechanism in human agency. Am Psychol 37(2):122-147. https://doi.org/10.1037/0003-066x.37.2. 122

Bull R (2013) What is 'believed' or actually 'known' about characteristics that may contribute to being a good/effective interviewer? Investigative Interviewing: Research and Practice 5:148-153

Bull R (2014) Investigative interviewing. Springer, New York. https://doi. org/10.1007/978-1-4614-9642-7

Celuch K, Kozlenkova I, Black G (2010) An exploration of self-efficacy as a mediator of skill beliefs and student self-identity as a critical thinker. Mark Educ Rev 20(3):255-264. https://doi.org/10.1177/ 0273475308324088

Cervone D, Peake PK (1986) Anchoring, efficacy, and action: the influence of judgmental heuristics on self-efficacy judgments and behavior. J Pers Soc Psychol 50(3):492-501. https://doi.org/10.1037/ 0022-3514.50.3.492

Chan J (2007) Police stress and occupational culture. Sociol Crime Law Deviance 8:129-151. https://doi.org/10.1016/s1521-6136(07) 08005-0

Cherryman J, Bull R (2001) Police officers' perceptions of specialist investigative interviewing skills. Int J Police Sci Manag 3(3):199 212. https://doi.org/10.1177/146135570100300302

Chin WW (2010) How to write up and report PLS analyses. In: Vinzi V, Chin WW, Henseler J, Wang H (eds) Handbook of partial least squares. Springer, Berlin, pp 655-690. https://doi.org/10.1007/ 978-3-540-32827-8 29 
Clarke C, Milne R (2001) A national evaluation of the PEACE investigative interviewing course. Home Office, London

Conner M, Armitage CJ (1998) Extending the theory of planned behavior: a review and avenues for further research. J Appl Soc Psychol 28(15):1429-1464. https://doi.org/10.1111/j.1559-1816.1998. tb01685.x

CPTU (1993) Developing interview skills. Central Planning and Training Unit, Harrogate

Crank JP (2010) Understanding police culture. Elsevier, London

Dando C, Bull R (2011) Maximising opportunities to detect verbal deception: training police officers to interview tactically. J Investig Psychol Offender Profiling 8:189-202. https://doi.org/10.1002/jip. 145

Dando C, Bull R, Ormerod T, Sandham A (2015) Helping to sort the liars from the truthtellers: the gradual revelation of information during investigative interviews. Leg Criminol Psychol 20(1):114-128. https://doi.org/10.1111/lcrp.12016

Davis S (2013) Sexual assault detectives' justifications for aggressive victim interviewing methods: a qualitative study, University of Nevada. Available at: http://digitalscholarship.unlv.edu/cgi/ viewcontent . cgi article $=2819 \&$ contex $t=$ thesesdissertations [Accessed: 12 Aug 2014]

Fahsing I, Ask K (2013) Decision making and decisional tipping points in homicide investigations: an interview study of British and Norwegian detectives. J Investig Psychol Offender Profiling 10(2): 155-165. https://doi.org/10.1002/jip.1384

Fishbein M, Ajzen I (1975) Belief, attitude, intention and behavior: an introduction to theory and research. Addison-Wesley, Reading

Fishbein M, Ajzen I (2010) Predicting and changing behavior: the reasoned action approach. Psychology, New York. https://doi.org/10. 4324/9780203838020

Freedman JL, Edwards DR (1988) Time pressure, task performance, and enjoyment. In: McGrath JE (ed) The social psychology of time. Sage, Newbury Park, pp 113-133

Gefen D, Straub D (2005) A practical guide to factorial validity using PLS-graph: tutorial and annotated example. Commun Assoc Inf Syst 16:91-109

Gottschalk P (2007) Organizational culture as determinant of enterprise information systems use in police investigations. Enterp Inf Syst 1(4):443-455. https://doi.org/10.1080/17517570701630412

Griffiths A (2008)An examination into the efficacy of police advanced investigative interview training. Unpublished $\mathrm{PhD}$ thesis. University of Portsmouth

Griffiths A, Walsh D (submitted) Qualitative analysis of qualitative evaluation: an exploratory examination of investigative interviewers' reflections on their performance. Psychol Crime Law

Hartwig M, Granhag PA, Vrij A (2005a) Police interrogation from a social psychology perspective. Polic Soc 15(4):379-399. https:// doi.org/10.1080/10439460500309956

Hartwig M, Granhag PA, Strömwall LA, Vrij A (2005b) Detecting deception via strategic disclosure of evidence. Law Hum Behav 29(4): 469-484. https://doi.org/10.1007/s10979-005-5521-x

Hartwig M, Granhag PA, Strömwall LA, Kronkvist O (2006) Strategic use of evidence during police interrogations: when training to detect deception works. Law Hum Behav 30(5):603-619. https://doi.org/ 10.1007/s10979-006-9053-9

Hartwig M, Granhag PA, Strömwall LA (2007) Guilty and innocent suspects' strategies during a police interrogation. Psychol Crime Law 13(2):213-227. https://doi.org/10.1080/10683160600750264

Hill C, Memon A, McGeorge P (2008) The role of confirmation bias in suspect interviews: a systematic evaluation. Leg Criminol Psychol 13(2):357-371. https://doi.org/10.1348/135532507x238682

Janis IL, Mann L (1977) Decision making: a psychological analysis of conflict, choice, and commitment. Free, New York

Janssen O (2001) Fairness perceptions as a moderator in the curvilinear relationships between job demands, and job performance and job satisfaction. Acad Manag J 44(5):1039-1050. https://doi.org/10. 2307/3069447

Kassin S (2008) The psychology of confessions. Annu Rev Law Sci 4(1): 193-217. https://doi.org/10.1146/annurev.lawsocsci.4.110707. 172410

Kassin SM, Goldstein CJ, Savitsky K (2003) Behavioral confirmation in the interrogation room: on the dangers of presuming guilt. Law Hum Behav 27(2):187-203. https://doi.org/10.1023/a:1022599230598

Kruglanski AW (1989) Lay epistemics and human knowledge: cognitive and motivational bases. Plenum, New York. https://doi.org/10.1007/ 978-1-4899-0924-4

Kruglanski AW (1996) A motivated gatekeeper of our minds: need-forclosure effects on interpersonal and group processes. In: Sorrentino RM, Higgins ET (eds) Handbook of motivation and cognition: the interpersonal context. Guilford, New York, pp 465-496

Kruglanski AW, Webster DM (1996) Motivated closing of the mind: "seizing" and "freezing". Psychol Rev 103(2):263-283. https:// doi.org/10.1037/0033-295x.103.2.263

Leo R (2008) Police interrogation and American justice. Harvard University Press, London. https://doi.org/10.4159/9780674033702

Lunenburg FC (2011) Self-efficacy in the workplace: implications for motivation and performance. Int J Manag Bus Adm 14:1-6

Lowry PB, Gaskin J (2014) Partial least squares (PLS) structural equation modeling (SEM) for building and testing behavioral causal theory: when to choose it and how to use it. IEEE Trans Prof Commun, Available: http://www.kolobkreations.com/PLSIEEETPC2014.pdf [Accessed: 15 Jul 2014] 57(2):123-146. https://doi.org/10.1109/tpc. 2014.2312452

McGurk BJ, Carr MJ, McGurk D (1993) Investigative interviewing courses for police officers: an evaluation. Police Research Series: Paper No. 4. Home Office: London

Milne R, Bull R (1999) Investigative interviewing, psychology and practice. Wiley, Chichester

Mortimer A, Shepherd E (1999) Frames of mind: schemata guiding cognition and conduct in the interviewing of suspected offenders. In: Memon A, Bull R (eds) Handbook of the psychology of interviewing. Wiley, Chichester, pp 293-315

Mortimer, A. (1994) Cognitive processes underlying police investigative interviewing behaviour. Unpublished $\mathrm{PhD}$ thesis. University of Portsmouth

National Crime Faculty (1996) Investigative interviewing: a practical guide. Training \& Development Unit, Bramshill

O'Neill M (2011) What makes a successful volume crime investigator? Unpublished $\mathrm{PhD}$ thesis. University of Portsmouth

Pajares F, Kranzler J (1995) Self-efficacy beliefs and general mental ability in mathematical problem-solving. Contemp Educ Psychol 20(4): 26-443. https://doi.org/10.1006/ceps.1995.1029

Pajares F, Schunk DH (2001) Self-beliefs and school success: self-efficacy, self-concept, and school achievement. In: Riding R, Rayner S (eds) Perception. Ablex, London, pp 239-266

Podsakoff PM, MacKenzie SB, Lee JY, Podsakoff NP (2003) Common method biases in behavioral research: a critical review of the literature and recommended remedies. J Appl Psychol 88(5):879-903. https://doi.org/10.1037/0021-9010.88.5.879

Rassin E, Eerland A, Kuijpers I (2010) Let's find the evidence: an analogue study of confirmation bias in criminal investigations. J Investig Psychol Offender Profiling 7(3):231-246. https://doi.org/ 10.1002/jip. 126

Roets A, Van Hiel A (2011) Item selection and validation of a brief, 15item version of the need for closure scale. Personal Individ Differ 50(1):90-94. https://doi.org/10.1016/j.paid.2010.09.004

Rossmo K (2009) Criminal investigation failures. CRC, Boca Raton. https://doi.org/10.1201/9781420047523

Schollum M (2005) Investigative interviewing: the literature. New Zealand Police, Wellington 
Schollum M (2006) Investigative interviewing: the current situation. New Zealand Police, Wellington

Scott A, Tudor-Owen J, Pedretti P, Bull R (2015) How intuitive is PEACE? Newly recruited police officers' plans, interviews and self-evaluations. Psychiatry Psychol Law 22(3):355-367. https:// doi.org/10.1080/13218719.2014.949397

Shepherd E, Griffiths A (2013) Investigative interviewing. Oxford University Press

Soukara S, Bull R, Vrij A (2002) Police detectives' aims regarding their interviews with suspects: any change at the turn of the millennium? Int J Police Sci Manag 4(2):101-114. https://doi.org/10.1177/ 146135570200400202

Stephenson GM, Moston S (2008) Police interrogation. Psychol Crime Law 1:151-157. https://doi.org/10.1080/10683169408411948

Teng CI, Hsiao FJ, Chou TA (2010) Nurse-perceived time pressure and patient-perceived care quality. J Nurs Manag 18(3):275-284. https:// doi.org/10.1111/j.1365-2834.2010.01073.x

Tong S, Bryant RP, Horvath MA (2009) Understanding criminal investigation. Wiley, Chichester. https://doi.org/10.1002/9780470682388

van der Sleen J (2009) A structure model for investigative interviewing of suspects. In: Bull R, Valentine T, Williamson T (eds) Handbook of psychology of investigative interviewing: current developments and future directions. Wiley-Blackwell, Chichester, pp 35-52

Walsh D, Bull R (2010) What really is effective in interviews with suspects? A study comparing interviewing skills against interviewing outcomes. Leg Criminol Psychol 15(2):305-321. https://doi.org/10. $1348 / 135532509 x 463356$
Walsh D, Bull R (2011) Benefit fraud investigative interviewing: a selfreport study of investigation professionals' beliefs concerning practice. J Investig Psychol Offender Profiling 8(2):131-148. https://doi. org/10.1002/jip.137

Walsh D, Bull R (2012) How do interviewers attempt to overcome suspects' denials? Psychiatry Psychol Law 19:151-168. https://doi.org/ 10.1080/13218719.2010.543756

Walsh D, Bull R (2015) The association between evidence disclosure strategies, questioning strategies, and interview outcomes. Psychol Crime Law 21(7):661-680. https://doi.org/10.1080/1068316x. 2015.1028544

Walsh D, Milne R (2007) Perceptions of benefit fraud staff in the UK: giving PEACE a chance? Public Adm 85(2):525-540. https://doi. org/10.1111/j.1467-9299.2007.00645.x

Walsh D, Milne R (2008) Keeping the PEACE? A study of investigative interviewing practices in the public sector. Leg Criminol Psychol 13(1):39-57. https://doi.org/10.1348/135532506x157179

Walsh D, King M, Neville A (2012) A formulation of agendas for future collaboration between practitioners and academics. Investigative interviewing: Research and. Practice 4:58-69

Walsh D, Oxburgh G, Redlich A, Myklebust T (eds) (2016) International developments and practices in investigative interviewing and interrogation, vol 2. Routledge, London

Walsh D, King M, Griffiths A (2017) Evaluating interviews which search for the truth with suspects: but are investigators' self-assessments of their own skills truthful ones? Psychol Crime Law 23(7):647-665. https://doi.org/10.1080/1068316X.2017.1296149 